\title{
Seeing through sedimented waters: environmental DNA reduces the phantom diversity of sharks and rays in turbid marine habitats
}

Yin Cheong Aden Ip ${ }^{1 *} \mathbb{D}$, Jia Jin Marc Chang ${ }^{1}$, Kelvin K. P. Lim², Zeehan Jaafar ${ }^{1}$, Benjamin J. Wainwright ${ }^{1,3}$ and Danwei Huang ${ }^{1,4,5}$

\begin{abstract}
Background: Sharks and rays are some of the most threatened marine taxa due to the high levels of bycatch and significant demand for meat and fin-related products in many Asian communities. At least $25 \%$ of shark and ray species are considered to be threatened with extinction. In particular, the density of reef sharks in the Pacific has declined to 3-10\% of pre-human levels. Elasmobranchs are thought to be sparse in highly urbanised and turbid environments. Low visibility coupled with the highly elusive behaviour of sharks and rays pose a challenge to diversity estimation and biomonitoring efforts as sightings are limited to chance encounters or from carcasses ensnared in nets. Here we utilised an eDNA metabarcoding approach to enhance the precision of elasmobranch diversity estimates in urbanised marine environments.
\end{abstract}

Results: We applied eDNA metabarcoding on seawater samples to detect elasmobranch species in the hyperurbanised waters off Singapore. Two genes—vertebrate 125 and elasmobranch $\mathrm{CO}$ - were targeted and amplicons subjected to Illumina high-throughput sequencing. With a total of 84 water samples collected from nine localities, we found 47 shark and ray molecular operational taxonomic units, of which 16 had species-level identities. When data were compared against historical collections and contemporary sightings, eDNA detected 14 locally known species as well as two potential new records.

Conclusions: Local elasmobranch richness uncovered by eDNA is greater than the seven species sighted over the last two decades, thereby reducing phantom diversity. Our findings demonstrate that eDNA metabarcoding is effective in detecting shark and ray species despite the challenges posed by the physical environment, granting a more consistent approach to monitor these highly elusive and threatened species.

Keywords: $12 \mathrm{~S}$ ribosomal RNA, Chondrichthyes, Cytochrome c oxidase subunit I, Dark diversity, Southeast Asia, Urban coastlines

*Correspondence: ycip@u.nus.edu

${ }^{1}$ Department of Biological Sciences, National University of Singapore, 16

Science Drive 4, Singapore 117558, Singapore

Full list of author information is available at the end of the article

\section{Background}

Sharks and rays are some of the most threatened marine taxa [1] due to their high demand as food fish [2], fin-related products in many Asian countries [3-5], Traditional Chinese Medicine [6], as well as high levels of bycatch [7]. Their slow growth $(5-10 \mathrm{~cm} /$ year), late 
maturity ( $5-15$ years), low fecundity (litter size $<100$ per year), and high ecological risk $[8,9]$ exacerbate the threats posed by overfishing and further hinder population recovery [10]. At least $25 \%$ of assessed shark and ray species are considered to be threatened with extinction based on the IUCN Red List of Threatened Species [7]. Specifically, the present density of sharks has declined to $3-10 \%$ of pre-human levels within Pacific coral reefs [11], and they are functionally extinct in $\sim 20 \%$ of reefs surveyed globally [12]. These megafauna therefore constitute a considerable portion of dark diversity-species that have been historically reported and still exist in the greater surrounds of their known geographic ranges, but are presently missing from a specific area [13]. They could also represent phantom diversity-extant species that are locally colonised but have become too rare to be detected by regular survey methods [14]. Failure to detect these large predators has conservation and management implications [15], and in some cases, learned avoidance behaviour of elasmobranchs further amplifies the challenges of monitoring these species [16].

The defaunation of sharks and rays have dire consequences for coral reef health $[17,18]$. It can alter biological communities [19], with impacts cascading down trophic levels [20]. Apart from the loss of ecosystem services conferred by these organisms, the disappearance of these megafauna would impede our understanding of the drivers of species distribution and resilience, curtailing efforts for the formulation and implementation of management strategies [17].

Marine habitats are threatened by a wide range of anthropogenic-induced stressors such as climate change [21], overfishing [12], pollution [22], and habitat degradation [23, 24]. Collectively, these impacts have led to population declines and extinctions [14, 25]. These consequently either increase an area's dark diversity due to extirpation of resident populations [13], or augment phantom diversity as these species may have left regular survey areas and are mistakenly regarded to be locally extinct [14]. From a conservation perspective, it is thus important to ascertain if non-detection is a result of the former or the latter because each has its own management implications. For instance, rediscovery of rare, phantom species can spur expansion of survey areas or improved techniques for monitoring success [14], while confirmed species losses might require further investigation into whether communityor ecosystem-level functions have been impacted and, if necessary, kickstart population recovery initiatives to allay further losses [13]. Clearly, the need to diversify survey methods for biomonitoring has never been greater.
Species detection can be a tall order in the marine realm, because these environments are comparatively less accessible and thus less well-studied compared to terrestrial environments [26]. Conventional biomonitoring methods, such as underwater visual census (UVCs) and baited remote underwater video stations (BRUVS), while fundamental for providing data to support the management of marine species, are time-consuming, labour- and cost-intensive [27]. These approaches may not always fare well for elusive fauna like low-density, highly-mobile sharks and rays [28]. Fortunately, recent advancements in DNA sequencing technologies $[29,30]$ have yielded new possibilities to work around present biomonitoring challenges. One such application is high-throughput sequencing (HTS) of organisms' trace genetic material isolated from environmental samples, otherwise known as environmental DNA (eDNA) [31, 32]. This approach allows for the detection of species in the water without having to visually observe them [33], and has emerged as an effective non-invasive method for biomonitoring based on different sample types (e.g. sediment; [34]) from various aquatic environments ranging from freshwater $[31,35]$ to marine habitats [36, 37]. In particular, eDNA has become increasingly popular for monitoring sharks and rays $[28,38-41]$.

This is a welcomed development for areas with highly sedimented ecosystems as eDNA can help bypass the constant need for visual observations [42, 43]. One example is Singapore, where the highly urbanised and turbid waters have hindered in-water studies of marine fauna [43-45]. As such, in-situ shark and ray sightings are sparse and typically comprise chance encounters (Jaafar pers. obs.; [44]) or carcasses [45]. The poor water visibility (average Secchi depths of $\sim 2 \mathrm{~m}$; [46]) encumbers visual detection and limits the resolution of underwater surveys and video capture technologies [12, 28], thus increasing phantom diversity. Moreover, avoidance behaviour [16] in certain elasmobranchs further complicates biomonitoring efforts. As such, it remains unclear as to whether elasmobranch diversity in Singapore can be accurately estimated from historical records. A previous broad-based eDNA metabarcoding study only managed to recover a single elasmobranch species, Carcharhinus melanopterus [47]. Yet, many other shark and ray species have been reported in checklists (e.g. [48] for fishes in the eastern Johor Strait), as well as from angler reports and citizen science surveys [49]. There is undoubtedly a striking gap in our understanding of elasmobranch diversity in urbanised environments that can be filled by a more targeted eDNA approach.

To detect the diversity of elasmobranch species present in Singapore's waters, this study targeted two genesvertebrate $12 \mathrm{~S}$ ribosomal RNA [50] and elasmobranch 
cytochrome $c$ oxidase subunit I $[28,38]$-from 84 water eDNA samples collected from nine localities for HTS. We compared our resulting eDNA data with historical collections and contemporary sightings to investigate the extent to which eDNA metabarcoding could uncover the phantom diversity of sharks and rays. Our findings not only help enhance our understanding of elasmobranch diversity in Singapore, they also demonstrate the utility of eDNA for studying mobile marine fauna in other turbid ecosystems. More broadly, this study and others will help inform biodiversity conservation and management practices by bringing eDNA methods closer to the routine biomonitoring of marine taxa and habitats [32, 51, 52].

\section{Results}

Illumina sequencing and primer efficiency

Illumina sequencing collectively produced 515,657,226 paired-end assembled reads, of which we obtained $13,209,521$ and 20,683,942 sequence reads (combined $33,893,463)$ from the $12 \mathrm{~S}$ and COI sequencing respectively. Only $33.1 \%$ unique sequence reads $(7,984,423$ for $12 \mathrm{~S}$ and $3,234,072$ for COI) were identifiable against GenBank records. A total of 210,761 (30,777 for $12 \mathrm{~S}$ and 179,984 for COI) unique sequence reads have closest matches ( $\geq 85 \%$ ) to 'Chondrichthyes' (Fig. 1), making up $1.88 \%$ of the total unique reads sequenced. Similar statistics were obtained previously [28]. The rest of the unique sequence reads were mostly represented by 'Actinopterygii' and other 'Metazoa'. Although $12 \mathrm{~S}$ sequencing produced a higher proportion of Actinopterygii relative to unique Chondrichthyes reads, the vertebrate-specific primers yielded more Chondrichthyes species units than COI (Fig. 1).

We detected shark and ray species in all the water samples $(n=84)$ while none were found in the negative controls. The COI sequencing had generated more reads per sample and more consistent detection across PCR replicates than $12 \mathrm{~S}$ sequencing (Additional file 1), especially for commonly detected species. Despite producing fewer total unique Chondrichthyes reads, the $12 \mathrm{~S}$ primers detected more species than the COI primers, but at much shallower read depths across PCR replicates (Additional file 1). Detection of sharks with the $12 \mathrm{~S}$ primers was observed to be less consistent among PCRs than the COI primer set.

\section{MOTU richness, phantom diversity and new records}

From all 84 water samples, eDNA recovered a total of 47 MOTUs consisting of 21 shark and 26 ray taxa that were identifiable to Chondrichthyes when matched against sequences on GenBank ( $\geq 90 \%$ for $12 \mathrm{~S}$ and $\geq 85 \%$ for COI; Additional files 2, 3). Sixteen of the 47 MOTUs, comprising five shark and 11 ray species, had specieslevel matches ( $\geq 98.3 \%$ for $12 \mathrm{~S}$ and $\geq 97 \%$ for COI), comprising 11, 10 and 5 MOTUs detected with $12 \mathrm{~S}, \mathrm{COI}$ and both markers, respectively (Fig. 2). Twenty-two MOTUs had $100 \%$ identity BLAST matches to multiple species in the GenBank database (e.g. Carcharhinus spp.; [53, 54]; Additional file 2) and were not analysed further.

Three sampling localities (CYR, RLH and LAZ) with the highest number of water samples $(n \geq 22)$ had species accumulation curves plateauing at 10-15 eDNA samples for species-identified MOTUs but continuing to increase for the all-MOTUs curve (Fig. 3A-C). While
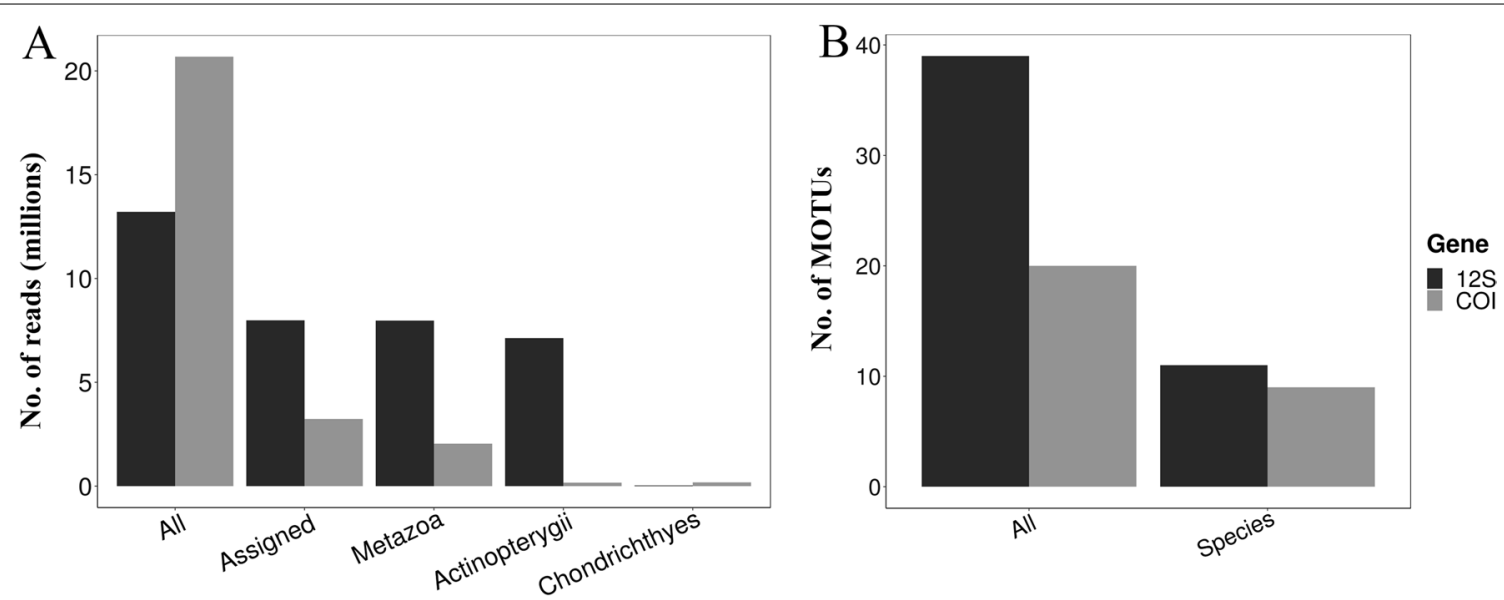

Fig. 1 Unique sequence reads recorded from sequencing with vertebrate 125 (black) or elasmobranch COI (grey) primers. A Total number of unique sequence reads generated from each gene and the relative proportions identifiable to sequences from GenBank ('Assigned'), from which they are segregated into the categories 'Metazoa,' 'Actinopterygii' and 'Chondrichthyes.' B Total number of Chondrichthyes MOTUs and named species units detected for each marker 


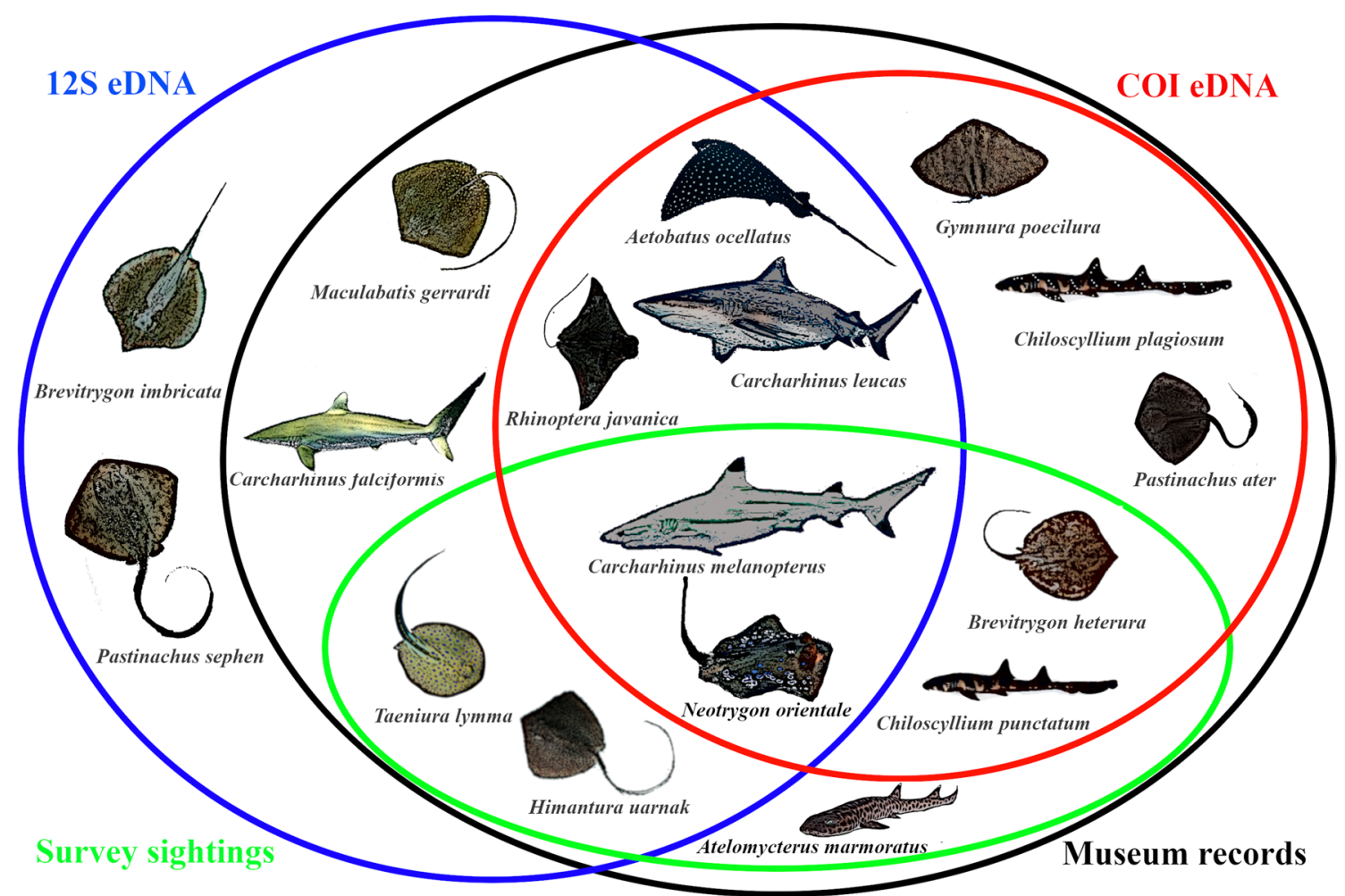

Fig. 2 Overlapping elasmobranch diversity in Singapore compiled from historical museum records (black), contemporary sightings (green), as well as species detected by eDNA metabarcoding of 125 (blue) and COI (red). Note that Neotrygon orientale is part of a species complex awaiting taxonomic revision [80]

non-saturation in the total MOTUs showed that 20 water samples were insufficient to capture elasmobranch diversity at each site, species accumulation appeared to saturate when all eDNA water samples across nine localities were analysed together $(n=84$; Fig. $3 \mathrm{D})$. The speciesidentified MOTUs curve plateaued at 16 MOTUs with $\sim 50$ water samples, while the total MOTUs curve plateaued at 47 MOTUs with $\sim 70$ water samples.

Historical records of elasmobranchs in Singapore comprised 37 elasmobranch species. Only seven species-three sharks and four rays-were sighted over the last two decades (Fig. 2, Additional file 2). The remaining 30 species from historical records not sighted recently constituted the pre-eDNA phantom diversity, amounting to $81.1 \%$ of the species records (Fig. 4). Our eDNA approach detected 16 species, including 14 overlapping with historical records (Additional file 2); and of the seven contemporary sightings, eDNA could detect all species except Atelomycterus marmoratus (Fig. 2; Additional file 2). Eight historically recorded species with no contemporary sightings that were rediscovered by eDNA represented 'unseen diversity' (Fig. 4; [28]). Therefore, the total number of contemporary records (contemporary sightings or eDNA) matching historical records was
15, up from seven pre-eDNA. Twenty-two species that were historically recorded but remained unaccounted for (even with eDNA) made up the post-eDNA phantom diversity at $59.5 \%$ of the historical species records (Fig. 4).

Two species-identified $12 \mathrm{~S}$ MOTUs that were not recorded prior to this study are potential new records for Singapore. They are two ray species (Brevitrygon imbricata and Pastinachus sephen) that were either found to have relatively high sequence read counts (133-1038, Additional file 2) or detected frequently among sites (Brevitrygon imbricata with multiple detections at LAZ; Pastinachus sephen at CYR and LAZ; Additional file 3).

\section{Distribution patterns and relative abundances}

Among the nine localities examined, Lazarus (LAZ; $S=13$ ), Cyrene Reef (CYR; $S=12$ ) and Raffles Lighthouse (RLH; $S=10$ ) had the highest total shark and ray diversity for the 16 MOTUs with species-level matches (Fig. 5). LAZ also recorded the highest ray diversity $(S=7)$, whereas CYR had the highest shark diversity $(S=5)$. The most commonly detected elasmobranchs were Carcharhinus melanopterus and Taeniura lymma; the former was detected across all nine sampling localities, while the latter was found in eight localities except Open Habitat Y 


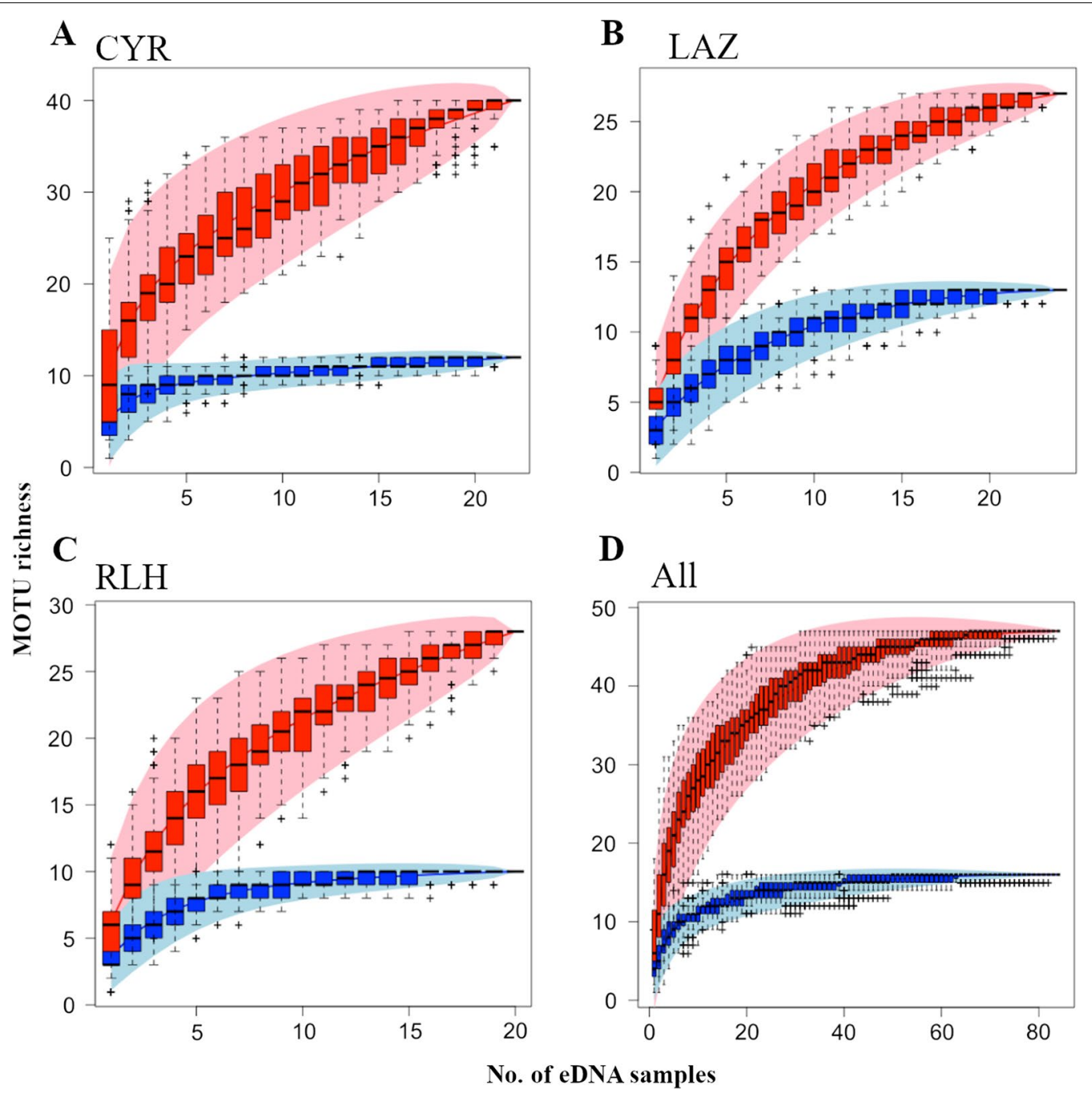

Fig. 3 Accumulation curves of MOTUs in water samples from A Cyrene Reefs (CYR), B Lazarus Island (LAZ), C Raffles Lighthouse (RLH), and D all sites. Pink curves represent all MOTUs, while blue curves represent only MOTUs with species-level identities. Shaded areas denote confidence intervals and boxplots show standard deviation

(OHY). Among the 31 unnamed MOTUs, Carcharhinus sp. 9 had the highest occurrence among sites (all 9 sites; Additional file 3) while Carcharhinus sp. 8 had the highest sequence read counts (up to 86,915; Additional file 2). Three other ray MOTUs, Himantura sp. 1, Himantura sp. 3 and Neotrygon sp. 3 also recorded high sequence read counts and/or abundance across sites.

The relative abundances of the 16 MOTUs with species-level matches varied considerably between and within sites (Fig. 6, Additional file 4). Six of these species were found to be highly abundant overall, accounting for $99.3 \%$ of all elasmobranch reads. In particular, Carcharhinus melanopterus reads were the most dominant at 6 of 9 sites ( $\geq 70.2 \%)$, although the remaining sites also had high abundances $(13.9 \%, 15.6 \%$ and $38.1 \%$ of reads at LAB, LSIS and CYR respectively). The latter sites were dominated by unique reads from ray species-Maculabatis gerrardi at CYR and Taeniura lymma at Little Sister's Island (LSIS) and Labrador Beach (LAB). Neotrygon orientale, Carcharhinus leucas and Chiloscyllium punctatum were also fairly abundant among sites (Fig. 6). The remaining 10 species had much lower abundances.

\section{Discussion}

eDNA reduces phantom diversity and uncovers potential new records

A total of 37 cartilaginous fish species have been recorded previously through natural history collections and visual observations in Singapore (Additional file 2). Only seven species have been sighted over the last two 


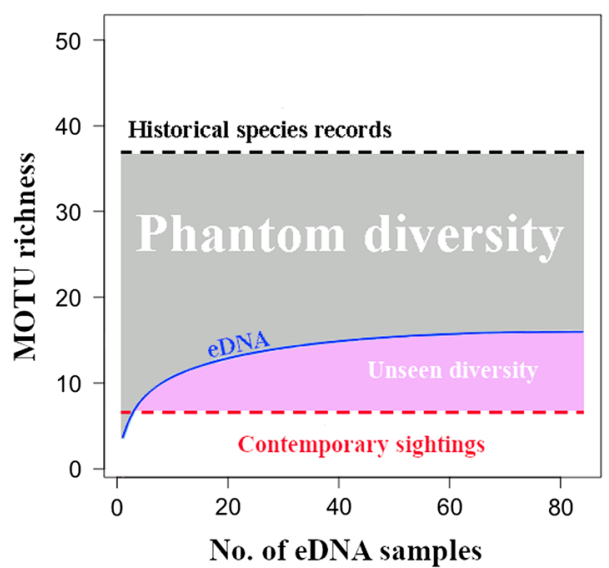

Fig. 4 Phantom diversity decreases with eDNA sampling, which uncovers the unseen diversity not detected by conventional methods such as specimen collection and visual survey. Note that one of the 17 contemporary records (contemporary sightings or eDNA), Atelomycterus marmoratus (coral catshark), was not detected by eDNA decades (Fig. 2, Additional file 2), which could be due to the poor water visibility [55] that makes visual detection challenging [47]. The pre-eDNA phantom diversity was therefore relatively high at $81.1 \%$ (30 species). We applied an eDNA approach and detected 47 shark and ray MOTUs, including 16 named species, from 84 water samples collected over a 3-year period. We detected nearly half of the named species in the historical species records, uncovered more than twice the diversity of species $(S=15)$ relative to contemporary sightings of seven species, and in turn reduced the phantom diversity to 59.5\% (Fig. 4, Additional file 2). Our results demonstrate that although a significant proportion of elasmobranch diversity has been missing from species records based on decades of visual sightings and conventional surveys, eDNA has revealed that these previously missed species remain present in Singapore's waters.

Collectively, the 84 eDNA samples captured considerable elasmobranch diversity, with 47 MOTUs or putative species, suggesting that more species are present than

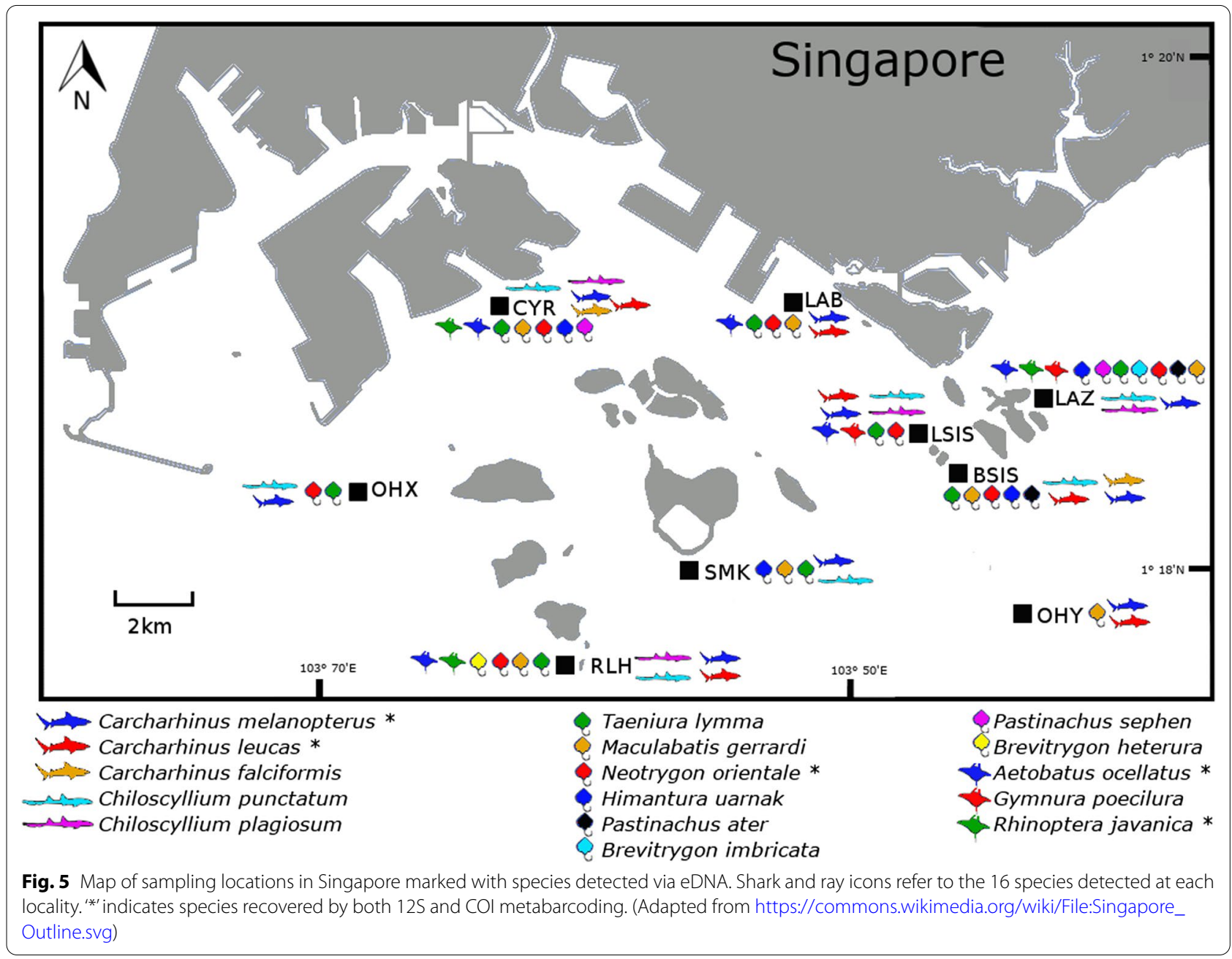




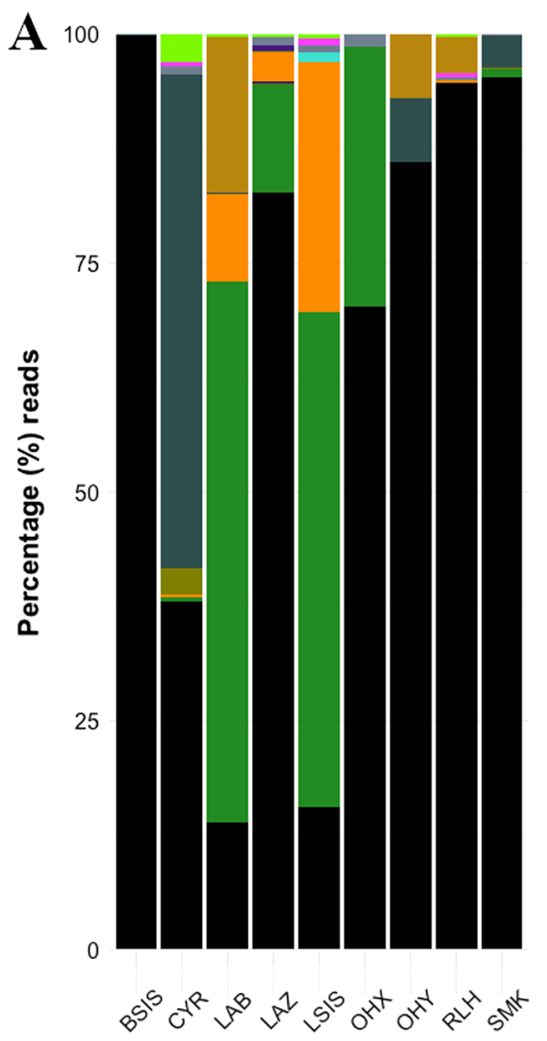

\section{B}

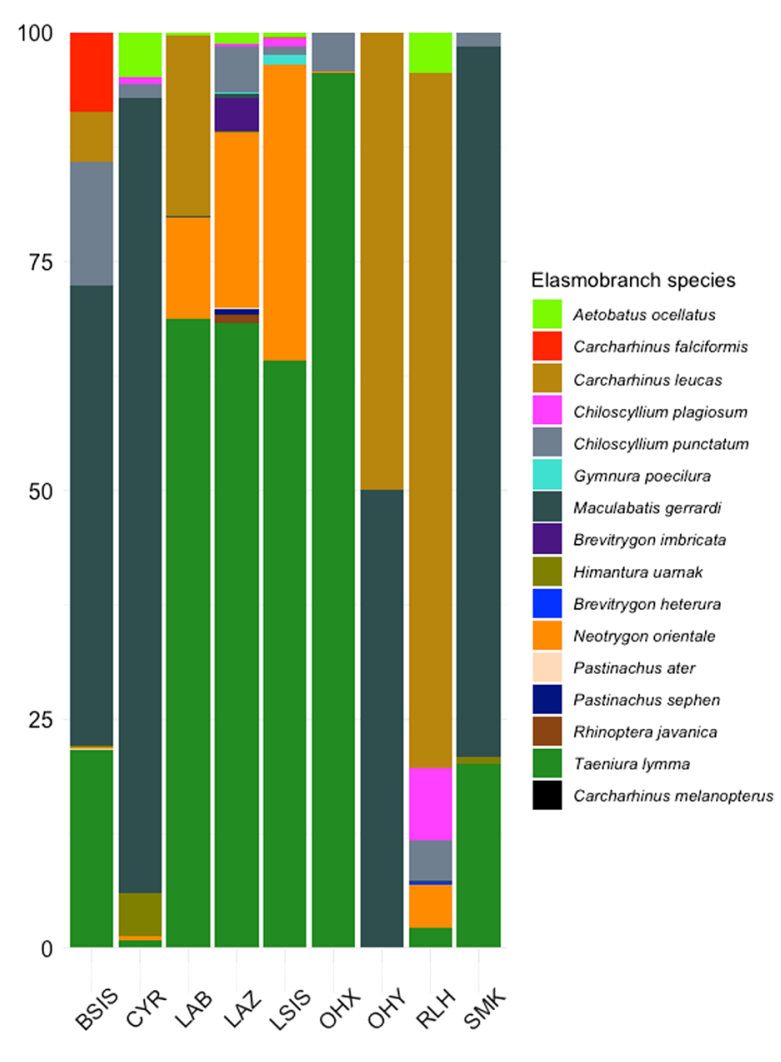

Fig. 6 Relative abundances of eDNA reads with species-level identification for all 16 elasmobranch species (A), and 15 species without Carcharhinus melanopterus (B)

known from Singapore $(S=37)$. The rapid saturation of the species accumulation curves for species-identified MOTUs exemplified the remarkable ability of eDNA to recover well-studied species. However, this low number of known species $(S=16)$ relative to all MOTUs $(S=47)$ demonstrated that there remain insufficient DNA barcodes covering a wide range of elasmobranch species for taxonomic matching of eDNA metabarcodes. These unidentified MOTUs could be new records or understudied taxa that are yet to be species-identified with proper reference DNA barcodes. More integrative taxonomic efforts in documenting biodiversity will help reduce phantom diversity even further, uncover new records and species, and expand databases to enhance eDNA biomonitoring [56-58]. More broadly, diversity estimates using eDNA can help drive targeted surveys in discovering and documenting more potential species in the species pool, and are also beneficial for providing updated richness estimates in areas that are expected to be more speciose but challenging to monitor.

To this end, we detected in the eDNA samples two species with no matching historical data and are potential new records for Singapore (Fig. 2)-Brevitrygon imbricata and Pastinachus sephen (Additional file 2). Earlier reports from Singapore under different names-Trygon imbricata and Hypolophus sephencould have alluded to these species [59,60]. Although these taxa underwent recent taxonomic revisions [61, 62], we have been unable to confirm their presence as there were no voucher specimens deposited at Singapore's Lee Kong Chian Natural History Museum (LKCNHM). Nevertheless, our eDNA sequences matched barcodes from samples that were collected from known ranges of $B$. imbricata and $P$. sephen [43]. These two MOTUs also have high sequence read counts (Additional file 2) or were detected at multiple sites (Fig. 5; Additional file 3), suggesting that their detection was unlikely an artefact of sequencing error. Moreover, Singapore is within the known natural distribution ranges of these two species [61, 62], supporting them as potential new local records. We emphasise that false positive detections cannot be ruled out completely in the HTS workflow [63], and thus encourage future work to validate the unseen diversity revealed here (Figs. 3, 4, species outside green circle). 


\section{Enhancing species detection and resolution}

While there are apparent advantages of eDNA metabarcoding-including its non-invasiveness and minimal reliance on manpower-critical methodological considerations such as locus and primer choices remain [64-66]. PCR primers and the targeted genes determine the taxonomic resolution at which eDNA metabarcodes can be identified. Our previous study found that universal metazoan primers were less efficient in elasmobranch species detection, with only one shark species found (Carcharhinus melanopterus; [47]) despite having 26 of 84 overlapping water samples. We therefore recommended taxon-specific metabarcoding primers for higher detection success of target species of interest [47], which we demonstrate here for 16 species-identified elasmobranchs. The shark-specific COI primers used here amplify a 127-bp region of a widely-used barcoding gene that has large reference databases (e.g. GenBank, BOLD) for sequence matching $[65,67,68]$ and for which there is sound understanding of its evolution [69-71]. However, these primers may be less efficient at amplifying a broad range of elasmobranch species and the targeted sequences may not have sufficient taxonomic resolution to delimit certain elasmobranch groups $[28,38,72]$. While COI primers with degenerate bases have been shown to increase the coverage of elasmobranch detection [73], the use of a single primer set can bias eDNA results and multiple markers should be used instead [74]. Therefore, the $12 \mathrm{~S}$ rRNA region, which also has comprehensive coverage in the reference databases [75], was amplified in this study for the broadest possible taxonomic coverage (see $[64,65])$.

The ambiguity of identification resulting from 100\% matches of some sequences to multiple species highlights either possibilities of matching to reference sequences that were incorrectly identified, or limited resolution of $12 \mathrm{~S}$ and COI for identifying a few elasmobranch taxa. Closer scrutiny of GenBank records is recommended to discern if these sequences match database entries that have been accurately identified and tagged with updated taxonomic names. To address the latter, alternative primers can be designed for longer target fragments ( $>200$-bp) to increase taxonomic resolution [76, 77]. Furthermore, conventional DNA barcoding research can prioritise these groups for database expansion, targeting alternative gene fragments which could yield higher resolution for species delimitation, including cytochrome b [78], control region [79] and NADH dehydrogenase subunit 2 [80]. These measures could aid in detecting 'expected' species at localities where they have been recorded and to preclude false negatives. Ultimately, improving primer design, targeting longer gene fragments (300-400-bp; [66]) and regions with higher variability will help enhance the taxonomic resolution of species detection, thereby harnessing the full potential of eDNA to better complement conventional methods in the conservation, management and biomonitoring of sharks and rays.

\section{Local conservation and management of elasmobranchs}

Compared to earlier studies focusing on shark detection in more pristine marine environments [28, 81], our study targeted elasmobranch species in an anthropogenically-impacted environment where shark diversity was expected to be low [38]. Indeed, our eDNA results detected just five sharks but 11 ray species across multiple localities (Fig. 2). These more than double the contemporary records of elasmobranchs in Singapore, suggesting that some diversity of elasmobranch fauna remains, albeit cryptically. This may likely be the case for other highly urbanised coastal environments as well. Moreover, the phantom diversity in Singapore has been reassessed here and is now lower (59.5\%) than before eDNA was applied (81.1\%; Fig. 4). Of the remaining 22 undetected species, only three-Telatrygon biasa, Temera hardwickii and Urogymnus granulatus-do not have either $12 \mathrm{~S}$ or COI sequences on GenBank. Implicitly, these species could have remained undetected by eDNA due to absence of reference sequences for species matching. Further investigations are needed for the 19 unaccounted species to discern if absences are due to limits of present eDNA methods or from local extirpations.

Formulation of conservation and management strategies typically require sightings data for taxa of concern $[12,82]$. This is challenging for elasmobranchs in urbanised, turbid environments such as Singapore due to the low water visibility. eDNA presents an alternative and viable method for monitoring multiple shark and ray species simultaneously, especially in areas where visually-reliant methods such as BRUVs, UVCs and drones are less effective. The ability of eDNA to complement visual methods will enable researchers to better assess the extent of declines and absences. To ascertain that the absences are due to actual extirpations and rule out learned avoidance behaviour of sharks in urban environments [16], we suggest integrating eDNA with visual methods to validate these possible losses so as to chart suitable policy pathways for management and restoration of elasmobranch populations [12].

Apart from being an alternative sampling method with more consistent detection results, the utility of eDNA goes beyond simply reducing phantom diversity [14, 28]. Accurate assessments of relative abundances are often thought to be challenging with most biases stemming from the use of universal primers for broad metabarcoding work [83], but it has become increasingly evident that using a multi-marker approach with several 
species-specific primers could effectively circumvent this issue [51, 74]. In particular, we used a combination of shark- and vertebrate-specific primers to infer relative abundances [84] of elasmobranchs in Singapore, data that are essential for robust management efforts. Mapping species distributions and estimating relative abundances of elasmobranch eDNA signals (Figs. 5, 6) highlighted potential diversity hotspots which are of conservation concern. For example, our data show that sites like CYR, LAZ and RLH host richer assemblages of sharks and rays, corroborating existing knowledge from citizen science records [49] that could lend further support for site protection measures. Furthermore, eDNA analysis here has expanded the local ranges of two ray species (Neotrygon orientale and Brevitrygon heterura), previously reported only along Singapore's northern coastline [49], to now include areas south of the main island (Fig. 5).

Despite overwhelming evidence supporting the viability of normalised read counts for abundance estimates [85], we acknowledge the associated limitations where eDNA can only provide rough assessments of relative abundances [83]. While biases from complex eDNA dynamics such as shedding rates between species remain to be addressed, body mass has been demonstrated to positively correlate with read counts especially for largersized organisms with higher DNA shedding rates [86], such as the elasmobranchs in this study [8]. The correspondence between relative abundance and frequency of visual observations (Additional file 4) also supports eDNA for quantitative measures [87]. Nevertheless, approaches such as the Hellinger transformation of read counts can enhance eDNA's reliability for quantifying abundances, and it must be emphasised that normalisation is required at the very least to avoid biased inferences [88]. Another potential workaround for improving abundance estimates involves the addition of internal DNA standards, where known DNA concentrations of non-target species are included into eDNA samples for copy number correction [89]. Collectively, these strategies can increase the confidence of quantifying abundances from eDNA metabarcoding results.

Relative abundance estimates of species that are of conservation concern can facilitate projections of their habitat preferences [90]. For instance, we detected six 'Vulnerable' species according to IUCN Red List of Threatened Species (IUCN 2020)-Aetobatus ocellatus, Carcharhinus falciformis, Carcharhinus melanopterus, Himantura uarnak, Maculabatis gerrardi and Rhinoptera javanica. We found three possible residency hotspots, such as BSIS for C. falciformis, LAZ for R. javanica, and CYR for A. ocellatus, $H$. uarnak and M. gerrardi, supporting more stringent site protection to conserve these threatened elasmobranchs. The current inability of eDNA methods to discern body sizes, sex and developmental stages of organisms [28] remains a key limitation in this case. Nevertheless, eDNA methods are ideal components of a comprehensive monitoring toolkit that can provide spatial information critical for formulating actionable management plans and policies [84, 91, 92].

\section{Conclusion}

We have here demonstrated the utility of eDNA detection of sharks and rays from HTS of seawater samples. By comparing our results with natural history collections and visual survey reports, we show that eDNA metabarcoding of seawater samples for elasmobranch detection in Singapore is a more viable and consistent approach to monitor these elusive species over survey sightings. Despite substantially reducing the phantom diversity of sharks and rays, the number of undetected yet expected species remains high $(S=22)$. On the one hand, these may represent dark diversity, or true local extinctions due to species' inability to thrive in a hyper-urbanised coastal environment. On the other hand, it could mean that a large number of elasmobranchs remain as phantom species in Singapore, having successfully evaded detection thus far, highlighting the urgent need to improve our biomonitoring methods so as to better understand and manage the numerous threats against elasmobranch populations here [28].

eDNA metabarcoding methods have shown enormous promise for complementing conventional methods in biomonitoring, species discovery and conservation applications. Emerging platforms can further propel eDNA's utility and relevance in these fields by providing opportunities for real-time eDNA metabarcoding with nanopore sequencing [81], improved species specificity with hybrid capture metabarcoding [93], as well as field detection with loop-mediated isothermal amplification assays (LAMP; [73]) and the 'Specific High-sensitivity Enzymatic Reporter un-LOCKing' method (SHERLOCK; [94, 95]). These novel approaches can be easily incorporated into field-ready laboratories for mobile biomonitoring [57]. Besides improving the design of higher-resolution primers to eradicate false negatives from the current eDNA experimental design, application of these new techniques may address many of the limitations here. For instance, the heightened single-species specificity with LAMP [73] can be used to search for the missing coral catshark (Fig. 2, Additional file 2) and for validating the presence of MOTUs detected solely by eDNA. The continual development and application of sensitive detection methods will further reduce phantom diversity and enhance our confidence in species absences and local extinctions. 
Beyond the abovementioned uses of eDNA, we are learning more about its applicability to more extensive and varied research problems, such as interpreting sequences for metaphylogeography [96] and studying intraspecific diversity [97]. With rapid advancements in detection technologies and increasingly diversified applications, eDNA is likely to play an increasingly significant role in biomonitoring, management and conservation, especially of threatened taxa and habitats.

\section{Methods}

\section{Water sampling and processing}

A total of $842-\mathrm{L}$ water samples were collected from the subtidal and intertidal areas at nine localities south of mainland Singapore between March 2017 and April 2019 (Fig. 5), of which 26 samples were from a previous study [47]. Subtidal sites were sampled at two depths, $1 \mathrm{~m}$ (shallow) and $10 \mathrm{~m}$ (deep) from the sea surface. The localities represented a variety of coastal environments, including coral reefs, seagrass, mangroves and open water habitats.

All water samples were collected under clear weather conditions. For subtidal sites, 2-L water samples were collected from a 5-L Van Dorn water sampler. Intertidal samples were collected by hand using two sterile 1-L bottles at each of two sampling points that were at least $10 \mathrm{~m}$ apart, starting with the first collection at a downstream position relative to the current and moving upstream for the second collection to reduce chances of contamination from the collectors. Water samples were kept on ice, transported back to the laboratory for vacuum-filtering through sterile nylon filter membranes (Thermo Scientific; diameter, $47 \mathrm{~mm}$; pore size, $0.22 \mu \mathrm{m}$ ) in autoclaved filter units, and subsequently stored at $-80{ }^{\circ} \mathrm{C}$. The time from collection to storage took $<2 \mathrm{~h}$.

Contamination control measures included cleaning of all working surfaces, laboratory apparatus and sampling equipment with $20 \%$ household bleach diluted with Milli-Q water. All collection bottles and filtration equipment (filter units and membranes) were autoclaved and disposable gloves were also disinfected with $20 \%$ bleach prior to use. All post-filtration work was performed in a biological safety cabinet. Negative controls for field collection, DNA extraction and polymerase chain reaction (PCR) were set up and processed in the same way as the samples to identify potential contamination; we used molecular-grade water in place of template DNA for the negative controls.

\section{eDNA extraction, amplification and sequencing}

Filter membranes were first incubated in $900 \mu \mathrm{L}$ $\mathrm{CTAB}$ (hexadecyltrimethylammonium bromide) with $20 \mu \mathrm{L}$ of $20 \mathrm{mg} / \mathrm{mL}$ proteinase $\mathrm{K}$ for $3 \mathrm{~h}$ at $55{ }^{\circ} \mathrm{C}$. The digest was then purified via phase separation with phenol:chloroform:isoamyl-alcohol (25:24:1) and incubated in $60 \%$ isopropanol for $16 \mathrm{~h}$ at $-30{ }^{\circ} \mathrm{C}$ to increase DNA recovery and yield.

For the metabarcoding assay, we amplified two gene fragments-12S-V5 ribosomal RNA and cytochrome $c$ oxidase subunit I (COI). The 12S-V5 locus (85-117-bp amplicon) was amplified using the ecoPrimers primer set, F: 5'-ACTGGGATTAGATACCCC-3', and R: 5'-TAG AACAGGCTCCTCTAG-3' [50]. For COI, we used two universal fish barcoding forward primers, FishF1: 5'-TCA ACCAACCACAAAGACATTGGCAC-3' and FishF2: 5'-TCGACTAATCATAAAGATATCGGCAC-3' [98], along with an elasmobranch-specific reverse primer SharkCOI-MINIR: 5'-AAGATTACAAAAGCGTGG GC-3' [99] to amplify a 127-bp fragment (see [28, 38]). Both $12 \mathrm{~S}$ and COI primers were respectively tagged with unique 9-bp or 8-bp sequence tags at the $5^{\prime}$ end to allow sequence-to-sample association in the downstream demultiplexing step [100]. We ensured that each reaction had its own unique sequence tag combination (for up to 96 unique tag combinations for each gene).

Five PCR replicates were performed for each gene per water sample, for a total of 840 reactions ( 84 samples $\times 5$ replicates $\times 2$ genes). Each PCR reaction mix, comprising a total volume of $25 \mu \mathrm{L}$, contained $0.5 \mu \mathrm{M}$ of each primer (Integrated DNA Technologies), $0.5 \mu \mathrm{g}$ bovine serum albumin (New England Biolabs), $25 \mathrm{mM}$ magnesium chloride (New England Biolabs), $5 \mu \mathrm{L}$ template DNA, 9.25 $\mu \mathrm{L}$ sterile water with $1 \mathrm{U}$ BioReady rTaq DNA polymerase with $1 \times$ reaction buffer $(\mathrm{v} / \mathrm{v})$ (Bulldog Bio Inc., China) for the $12 \mathrm{~S}$ vertebrate primers, and $12.5 \mu \mathrm{L}$ of GoTaq DNA polymerase for the elasmobranch COI primers. The thermal cycling profile for $12 \mathrm{~S}-\mathrm{V} 5$ was $95{ }^{\circ} \mathrm{C}$ for $7 \mathrm{~min}, 36$ cycles of $94{ }^{\circ} \mathrm{C}$ for $30 \mathrm{~s}, 52{ }^{\circ} \mathrm{C}$ for $30 \mathrm{~s}$, $72{ }^{\circ} \mathrm{C}$ for $40 \mathrm{~s}$, and a final extension for $5 \mathrm{~min}$ at $72{ }^{\circ} \mathrm{C}$; while for COI it was $95^{\circ} \mathrm{C}$ for $15 \mathrm{~min}, 36$ cycles of $94{ }^{\circ} \mathrm{C}$ for $1 \mathrm{~min}, 52{ }^{\circ} \mathrm{C}$ for $1 \mathrm{~min}, 72{ }^{\circ} \mathrm{C}$ for $1 \mathrm{~min}$, and a final extension for $5 \mathrm{~min}$ at $72{ }^{\circ} \mathrm{C}$. Amplification success was verified on $2 \%$ agarose gels stained with GelRed (Cambridge Bioscience).

A total of 840 tagged amplicon samples and 940 negative controls were then combined into 20 pools (up to 96 unique PCR reactions each; see above) and cleaned using 1.5-1.8 $\times$ AMPure XP magnetic beads (Beckman Coulter). PCR-free library preparation was performed where each of these 20 library pools were further multiplexed with unique Illumina adapters (Set B), using NEBNext Ultra II DNA Library Prep Kit (New England Biolabs) following manufacturer's protocol up to the adapter ligation step (i.e. no PCR enrichment). The libraries were pooled in equimolar ratios and outsourced to the Genome Institute of Singapore for sequencing over three lanes of Illumina HiSeq $4000(151 \times 151$-bp paired ends), each spiked 
with $20 \%$ PhiX to improve base diversity. We allocated a sequencing depth of up to 1 million reads per amplicon sample to increase the detection chances of rare taxa [101].

\section{Bioinformatics and data analyses}

Illumina paired-end reads were merged using PEAR v0.9.11 [102]. Maximum assembly length $(m)$ was set at 200-bp and quality score threshold $(q)$ was set at 20 . Minimum assembly length ( $n$ ) was set to 100 -bp and 80-bp for $12 \mathrm{~S}$ and COI respectively. OBITools v1.2.11 [103] was used for demultiplexing and further processing of assembled reads. As we previously observed that a poorer quality of reverse reads would affect the integrity of the reverse barcode tags and in turn, lower demultiplexing efficacy [47], we demultiplexed sequence reads to respective PCR replicates using only the unique forward primer tag. For demultiplexing via ngsfilter, we used the default settings, where no mismatch was allowed for barcode tags, while up to two mismatches were allowed for the primer sequences. Following which, cutadapt v1.18 [104] was used to remove the reverse primer and tag sequences. All successfully demultiplexed and primerfree reads were concatenated into a single file, sequence records grouped, and dereplicated using obiuniq. Finally, sequences were binned into PCR replicate files using obisubset.

The dataset was filtered for metazoan sequences using BLASTn implemented on BLAST+ v2.8.1 [105] to match against the NCBI $n t$ database (downloaded 2nd September 2019), retaining only sequence reads with $\geq 80 \%$ sequence similarity. The output was parsed with readsidentifier v1.0 [106] to obtain preliminary taxonomic identities of each sequence. Only sequences assigned to 'Chondrichthyes' ( $\geq 80 \%$ sequence similarity) were retained for further analyses. This step also allowed us to eliminate non-target reads from the dataset.

Quality filters were applied to eliminate reads with amplification and sequencing errors, while ensuring that read coverage was comparable across samples. We implemented a read count filter for each PCR replicate based on a relative threshold. Only sequences whose abundance exceeded $0.0001\left(1 \mathrm{e}^{-4}\right)$ of the total read count for the PCR replicate were used in the analyses; i.e., sequences in replicates with higher read counts have to meet a higher threshold in order to be retained for analysis. To implement this filter, we used the obistat module to summarise the total read count per replicate file. However, in some of the $1 \mathrm{e}^{-4}$ datasets, we found that singleton reads had met the threshold. These were subsequently excluded by setting a minimum read count of $\geq 2$ with obigrep, which was also set to retain sequences of lengths 90-140bp and $80-120-$ bp for $12 \mathrm{~S}$ and COI respectively. We then used obiclean to collapse sequences with potential PCR sequencing errors into respective unique sequence reads. Sequences from sample PCR replicates were also matched against sequences found in the negative PCRs; although none of these sequences were elasmobranch sequences, they were still deemed potential contaminants and removed from downstream analyses.

Taxonomic assignment was performed by applying respective species delimitation thresholds (class-level identity $\geq 90 \%$ for $12 \mathrm{~S}$ and $\geq 85 \%$ for COI; species-level identity $\geq 98.3 \%$ for $12 \mathrm{~S}$ [43] and $\geq 97 \%$ for COI [107] for each gene (Additional file 2) to collapse the unique sequence reads into MOTUs [108]. We eliminated potential false positives by removing MOTUs present in only one PCR replicate and/or taxa that have documented ranges outside the Indo-Pacific. Additionally, MOTUs that were (i) not assigned species-level identities, or (ii) matched at high percentages $(99-100 \%)$ to multiple taxa within the same or different genera respectively were also removed.

To estimate elasmobranch species richness, we plotted species accumulation curves for all MOTUs and MOTUs with species-level identities against number of water samples collected using the specaccum function [109] of vegan v2.5 package [110] in RStudio (R Core Team, 2017). Sequence read counts were normalised by sample read depth to estimate the relative abundances of elasmobranch species [88].

\section{Compiling historical species records}

Records of elasmobranch species reported from Singapore (not via eDNA) were consolidated through three different sources. First, historical records of shark and ray species (from the 1960s) were obtained from the collection at LKCNHM. Second, contemporary sightings were compiled from two decades of citizen-science reports (20002019), supported by in-situ images, and obtained from WildSingapore (http://www.wildsingapore.com/wildfacts; [49]). Third, elasmobranch species documented in the grey literature from 2003 to 2019 were also compiled, and these were noted to fully overlap with both historical records and contemporary sightings. We then integrated all three datasets, removing overlapping records to estimate phantom diversity before and following the application of eDNA in this study (Additional file 2).

\section{Abbreviations}

BLAST: Basic local alignment search tool; BRUV: Baited remote underwater video; BSIS: Big Sisters'Island; COI: Cytochrome c oxidase subunit I; CYR: Cyrene reefs; eDNA: Environmental DNA; HTS: High-throughput sequencing; IUCN: International Union for Conservation of Nature; LAB: Labrador; LAMP: Loopmediated isothermal amplification; LAZ: Lazarus Island; LKCNHM: Lee Kong Chian Natural History Museum; LSIS: Little Sisters' Island; MOTU: Molecular operational taxonomic unit; OHX: Open habitat X; OHY: Open habitat Y; PCR: 
Polymerase chain reaction; RLH: Raffles Lighthouse; SHERLOCK: Specific Highsensitivity Enzymatic Reporter un-LOCKing; SMK: Semakau; UVC: Underwater visual census.

\section{Supplementary Information}

The online version contains supplementary material available at https://doi. org/10.1186/s12862-021-01895-6.

Additional file 1. Heatmap illustrating $\log _{10}$ sequence read counts for all 16 Chondrichthyes species detected by both 125 and COI across all PCR replicates.

Additional file 2. Known Chondrichthyes species diversity in Singapore, compiled from museum records and sighting reports marked with $\boldsymbol{} \checkmark$ and from eDNA metabarcoding marked with ' +' 'Taxonomic assignments, read counts and database match information are indicated only for MOTUs detected by eDNA in this study.

Additional file 3. Heatmap of all MOTUs and respective percentage matches to sequences from GenBank database. See Additional file 2 for taxonomic assignments for each MOTU.

Additional file 4. Species abundance patterns of the six contemporary sighted species are found to be in agreement with relative abundance from eDNA, as shown in the plots of survey sightings frequency against their respective eDNA sample detection frequencies (A), and number of sites where they were seen during surveys against number of sites with eDNA detection (B).

Additional file 5. Sample demultiplexing information.

\section{Acknowledgements}

The computational work for this article was partially performed on resources of the National Supercomputing Centre, Singapore (https://www.nscc.sg).

\section{Authors' contributions}

YCAI, JJMC, BJW, and DH conceived the idea and secured study funding. YCAI and JJMC collected the samples. KKPL, YCAI, JJMC, and ZJ compiled and curated the species records. YCAI performed the molecular work and data analysis, with input from all other authors. YCAI, JJMC, and DH drafted the manuscript. All authors read and approved the final manuscript, and declare no conflicts of interest.

\section{Funding}

This research was supported by the Ah Meng Memorial Conservation Fund (R-154-000-B39-720), and the National Research Foundation, Prime Minister's Office, Singapore, under the Marine Science R\&D Programme (MSRDP-P03). The funders had no role in the design of the study; in the collection, analyses, or interpretation of data; in the writing of the manuscript, or in the decision to publish the results.

\section{Availability of data and materials}

Raw sequence reads generated in this study have been uploaded to GenBank NCBI Sequence Read Archive under BioProject PRJNA673533 (SRR15093454SRR15093473) [111]. Additional file 5 contains the sample demultiplexing information.

\section{Declarations}

\section{Ethics approval and consent to participate}

Water sample collections were authorised by the National Parks Board (Permit number NP/RP15-014 and NP/RP15-088).

\section{Consent for publication}

Not applicable.

\section{Competing interests}

The authors declare that they have no competing interests.

\section{Author details}

${ }^{1}$ Department of Biological Sciences, National University of Singapore, 16 Science Drive 4, Singapore 117558, Singapore. ${ }^{2}$ Lee Kong Chian Natural History Museum, National University of Singapore, 2 Conservatory Drive, Singapore 117377, Singapore. ${ }^{3}$ Yale-NUS College, National University of Singapore, 16 College Avenue West, Singapore 138527, Singapore. ${ }^{4}$ Centre for Nature-based Climate Solutions, National University of Singapore, 16 Science Drive 4, Singapore 117558, Singapore. ${ }^{5}$ Tropical Marine Science Institute, National University of Singapore, 18 Kent Ridge Road, Singapore 119227 , Singapore.

Received: 27 April 2021 Accepted: 20 August 2021

Published online: 06 September 2021

\section{References}

1. Davidson LNK, Dulvy NK. Global marine protected areas to prevent extinctions. Nat Ecol Evol. 2017;1(2):40.

2. Ya BP. The shark and ray trade in Singapore. Traffic International. $2017 ; 713$

3. Lam VYY, de Mitcheson YS. The sharks of South East Asia-unknown, unmonitored and unmanaged. Fish Fish. 2011;12(1):51-74.

4. Myers RA, Worm B. Rapid worldwide depletion of predatory fish communities. Nature. 2003;423(6937):280-3.

5. Steinke D, Bernard AM, Horn RL, Hilton P, Hanner R, Shivji MS. DNA analysis of traded shark fins and mobulid gill plates reveals a high proportion of species of conservation concern. Sci Rep. 2017;7(1):9505.

6. O'Malley MP, Townsend KA, Hilton P, Heinrichs S, Stewart JD. Characterization of the trade in manta and devil ray gill plates in China and South-east Asia through trader surveys. Aquat Conserv Mar Freshw Ecosyst. 2017;27(2):394-413.

7. Dulvy NK, Fowler SL, Musick JA, Cavanagh RD, Kyne PM, Harrison LR, et al. Extinction risk and conservation of the world's sharks and rays. Life. 2014;3:e00590.

8. Frisk MG, Miller TJ, Fogarty MJ. Estimation and analysis of biological parameters in elasmobranch fishes: a comparative life history study. Can J Fish Aquat Sci. 2001;58(5):969-81.

9. Patterson HM, Tudman MJ. Chondrichthyan guide for fisheries managers: a practical guide for fisheries managers. 2009. 70 p.

10. Hobday AJ, Smith ADM, Stobutzki IC, Bulman C, Daley R, Dambacher $\mathrm{JM}$, et al. Ecological risk assessment for the effects of fishing. Fish Res. 2011;108(2-3):372-84.

11. Nadon MO, Baum JK, Williams ID, McPherson JM, Zgliczynski BJ, Richards BL, et al. Re-creating missing population baselines for Pacific reef sharks. Conserv Biol. 2012;26(3):493-503.

12. MacNeil MA, Chapman DD, Heupel M, Simpfendorfer CA, Heithaus M, Meekan M, et al. Global status and conservation potential of reef sharks. Nature. 2020;583(7818):801-6.

13. Pärtel M, Szava-Kovats R, Zobel M. Dark diversity: shedding light on absent species. Trends Ecol Evol. 2011;26(3):124-8.

14. Beck JJ, Larget B, Waller DM. Phantom species: adjusting estimates of colonization and extinction for pseudo-turnover. Oikos. 2018;127(11):1605-18.

15. Stevenson C, Katz LS, Micheli F, Block B, Heiman KW, Perle C, et al. High apex predator biomass on remote Pacific islands. Coral Reefs. 2007;26(1):47-51

16. Mourier J, Brown C, Planes S. Learning and robustness to catch-andrelease fishing in a shark social network. Biol Lett. 2017;13(3):20160824.

17. Sandin SA, Smith JE, Demartini EE, Dinsdale EA, Donner SD, Friedlander $A M$, et al. Baselines and degradation of coral reefs in the Northern Line Islands. PLoS ONE. 2008:3(2):e1548.

18. Miller J, Maragos J, Brainard R, Asher J, Vargas-Ángel B, Kenyon, J, et al. The state of coral reef ecosystems of the Pacific Remote Island Areas. In: The state of coral reef ecosystems of the United States and Pacific Freely Associated States. 2008; 3542386

19. Bascompte J, Melián CJ, Sala E. Interaction strength combinations and the overfishing of a marine food web. Proc Natl Acad Sci USA. 2005;102(15):5443-7.

20. Mumby PJ. Fishing, trophic cascades, and the process of grazing on coral reefs. Science. 2006;311(5757):98-101. 
21. Hoegh-Guldberg O, Bruno JF. The impact of climate change on the world's marine ecosystems. Science. 2010;328(5985):1523-8.

22. Todd PA, Ong X, Chou LM. Impacts of pollution on marine life in Southeast Asia. Biodivers Conserv. 2010;19(4):1063-82.

23. Heery EC, Hoeksema BW, Browne NK, Reimer JD, Ang PO, Huang $D$, et al. Urban coral reefs: degradation and resilience of hard coral assemblages in coastal cities of East and Southeast Asia. Mar Pollut Bull. 2018;135:654-81.

24. Travis JMJ. Climate change and habitat destruction: a deadly anthropogenic cocktail. Proc Biol Sci. 2003;270(1514):467-73.

25. Poquita-Du RC, Quek ZBR, Jain SS, Schmidt-Roach S, Tun K, Heery $E C$, et al. Last species standing: loss of Pocilloporidae corals associated with coastal urbanization in a tropical city state. Mar Biodivers. 2019;49(4):1727-41.

26. Webb TJ, Mindel BL. Global patterns of extinction risk in marine and non-marine systems. Curr Biol. 2015;25(4):506-11.

27. Keith D, Resit Akçakaya H, Butchart SHM, Collen B, Dulvy NK, Holmes $\mathrm{EE}$, et al. Temporal correlations in population trends: conservation implications from time-series analysis of diverse animal taxa. Biol Conserv. 2015;192:247-57.

28. Boussarie G, Bakker J, Wangensteen OS, Mariani S, Bonnin L, Juhel J-B, et al. Environmental DNA illuminates the dark diversity of sharks. Sci Adv. 2018;4(5):eaap9661.

29. Baird DJ, Hajibabaei M. Biomonitoring 2.0: a new paradigm in ecosystem assessment made possible by next-generation DNA sequencing. Mol Ecol. 2012;21(8):2039-44.

30. Shokralla S, Spall JL, Gibson JF, Hajibabaei M. Next-generation sequencing technologies for environmental DNA research. Mol Ecol. 2012;21(8):1794-805.

31. Ficetola GF, Miaud C, Pompanon F, Taberlet P. Species detection using environmental DNA from water samples. Biol Let. 2008:4(4):423-5.

32. Thomsen PF, Willerslev E. Environmental DNA —an emerging tool in conservation for monitoring past and present biodiversity. Biol Conserv. 2015;183:4-18.

33. Jerde CL, Mahon AR, Lindsay Chadderton W, Lodge DM. "Sightunseen" detection of rare aquatic species using environmental DNA. Conserv Lett. 2011;4(2):150-7.

34. Barrenechea Angeles I, Lejzerowicz F, Cordier T, Scheplitz J, Kucera M, Ariztegui $\mathrm{D}$, et al. Planktonic foraminifera eDNA signature deposited on the seafloor remains preserved after burial in marine sediments. Sci Rep. 2020;10(1):20351.

35. Lim NKM, Tay YC, Srivathsan A, Tan JWT, Kwik JTB, Baloğlu B, et al. Next-generation freshwater bioassessment: eDNA metabarcoding with a conserved metazoan primer reveals species-rich and reservoirspecific communities. R Soc Open Sci. 2016;3(11):160635.

36. Foote AD, Thomsen PF, Sveegaard S, Wahlberg M, Kielgast J, Kyhn $L A$, et al. Investigating the potential use of environmental DNA (eDNA) for genetic monitoring of marine mammals. PLOS ONE. 2012;7(8):e41781

37. Thomsen PF, Møller PR, Sigsgaard EE, Knudsen SW, Jørgensen OA, Willerslev E. Environmental DNA from seawater samples correlate with trawl catches of subarctic, deepwater fishes. PLoS ONE. 2016;11(11):e0165252.

38. Bakker J, Wangensteen OS, Chapman DD, Boussarie G, Buddo D, Guttridge $T L$, et al. Environmental DNA reveals tropical shark diversity in contrasting levels of anthropogenic impact. Sci Rep. 2017;7(1):16886.

39. Gargan LM, Morato T, Pham CK, Finarelli JA, Carlsson JEL, Carlsson J. Development of a sensitive detection method to survey pelagic biodiversity using eDNA and quantitative PCR: a case study of devil ray at seamounts. Mar Biol. 2017;164(5):112.

40. Schweiss KE, Lehman RN, Marcus Drymon J, Phillips NM. Development of highly sensitive environmental DNA methods for the detection of Bull Sharks, Carcharhinus leucas (Müller and Henle, 1839), using Droplet DigitalTM PCR. Environ DNA. 2020;2(1):3-12.

41. West KM, Stat M, Harvey ES, Skepper CL, DiBattista JD, Richards ZT, et al. eDNA metabarcoding survey reveals fine-scale coral reef community variation across a remote, tropical island ecosystem. Mol Ecol. 2020;29(6):1069-86.

42. DiBattista JD, Coker DJ, Sinclair-Taylor TH, Stat M, Berumen ML, Bunce M. Assessing the utility of eDNA as a tool to survey reef-fish communities in the Red Sea. Coral Reefs. 2017;36(4):1245-52.
43. Sigsgaard EE, Torquato F, Frøslev TG, Moore ABM, Sørensen JM, Range P, et al. Using vertebrate environmental DNA from seawater in biomonitoring of marine habitats. Conserv Biol. 2020;34(3):697-710.

44. Tun KPP, Lim KKP. Brown-banded bamboo shark off Pulau Satumu. Singapore Biodiversity Records. 2015;79.

45. Chim CK, Lee YL, Tong S, Tay T, Ong R. Blacktip reef sharks caught in trammel nets at Lazarus Island. Singapore Biodiv Records. 2015;158-9.

46. Bramante JF, Raju DK, Sin TM. Multispectral derivation of bathymetry in Singapore's shallow, turbid waters. Int J Remote Sens. 2013;34(6):2070-88

47. I Y YCA, Tay YC, Chang JJM, Ang HP, Tun KPP, Chou LM, et al. Seeking life in sedimented waters: environmental DNA from diverse habitat types reveals ecologically significant species in a tropical marine environment. Environ DNA. 2021;3(3):654-68.

48. $\mathrm{Ng} \mathrm{HH}$, Tan HH, Lim KKP, Ludt WB, Chakrabarty P. Fishes of the Eastern Johor Strait. Raffles Bull Zool. 2015;31:303-37.

49. Lim LJW, Loh JBY, Lim AJS, Tan BYX, Ip YCA, Neo ML, et al. Diversity and distribution of intertidal marine species in Singapore. Raffles Bull Zool. 2020;68:396-403.

50. Riaz T, Shehzad W, Viari A, Pompanon F, Taberlet P, Coissac E. ecoPrimers: inference of new DNA barcode markers from whole genome sequence analysis. Nucleic Acids Res. 2011;39(21):e145.

51. Beng KC, Corlett RT. Applications of environmental DNA (eDNA) in ecology and conservation: opportunities, challenges and prospects. Biodivers Conserv. 2020;29(7):2089-121.

52. Bohmann K, Evans A, Gilbert MTP, Carvalho GR, Creer S, Knapp M, et al. Environmental DNA for wildlife biology and biodiversity monitoring. Trends Ecol Evol. 2014;29(6):358-67.

53. Dosay-Akbulut M. The phylogenetic relationship within the genus Carcharhinus. C R Biol. 2008;331(7):500-9.

54. Naylor GJP. The phylogenetic relationships among requiem and hammerhead sharks: inferring phylogeny when thousands of equally most parsimonious trees results. Cladistics. 1992;8:295-318.

55. Chou LM, Huang D, Tan KS, Toh TC, Goh BPL, Tun K. Chapter 24_-Singapore. In: Sheppard C, editor. World seas: an environmental evaluation. London: Academic Press; 2019. p. 539-58.

56. Chang JJM, IP YCA, Bauman AG, Huang D. MinION-in-ARMS: nanopore sequencing to expedite barcoding of specimen-rich macrofaunal samples from autonomous reef monitoring structures. Front Mar Sci. 2020;7:448.

57. Chang JJM, I Y YCA, Ng CSL, Huang D. Takeaways from mobile DNA barcoding with BentoLab and MinION. Genes. 2020:11(10):1121.

58. I Y YCA, Tay YC, Gan SX, Ang HP, Tun K, Chou LM, et al. From marine park to future genomic observatory? Enhancing marine biodiversity assessments using a biocode approach. Biodivers Data J. 2019;7:e46833.

59. Bleeker P. Bijdrage tot de kennis der ichthyologische fauna van Singapore. Nat Tijdschr Neder Indie. 1852;3:51-86.

60. Cantor T. Catalogue of Malayan fishes. In: Baptist Mission Press. 1849.

61. Last P, White W, Séret B, Naylor G, de Carvalho M, Stehmann M. Rays of the world. Clayton: CSIRO Publishing; 2016. p. 800.

62. Manjaji-Matsumoto BM, Last PR, White WT. Brevitrygon imbricata. The IUCN Red List of Threatened Species. 2016.

63. Darling JA, Pochon X, Abbott CL, Inglis GJ, Zaiko A. The risks of using molecular biodiversity data for incidental detection of species of concern. Divers Distrib. 2020;26(9):1116-21.

64. DiBattista JD, Reimer JD, Stat M, Masucci GD, Biondi P, De Brauwer M, et al. Environmental DNA can act as a biodiversity barometer of anthropogenic pressures in coastal ecosystems. Sci Rep. 2020;10(1):8365.

65. Stat M, Huggett MJ, Bernasconi R, DiBattista JD, Berry TE, Newman SJ, et al. Ecosystem biomonitoring with eDNA: metabarcoding across the tree of life in a tropical marine environment. Sci Rep. 2017;7(1):12240.

66. Zhang S, Zhao J, Yao M. A comprehensive and comparative evaluation of primers for metabarcoding eDNA from fish. Methods Ecol Evol. 2020:11(12):1609-25.

67. Andújar C, Arribas P, Yu DW, Vogler AP, Emerson BC. Why the COI barcode should be the community DNA metabarcode for the metazoa. Mol Ecol. 2018;27(20):3968-75.

68. Leray M, Knowlton N, Ho S-L, Nguyen BN, Machida RJ. GenBank is a reliable resource for 21st century biodiversity research. Proc Natl Acad Sci USA. 2019;116(45):22651-6. 
69. Kwong S, Srivathsan A, Vaidya G, Meier R. Is the COI barcoding gene involved in speciation through intergenomic conflict? Mol Phylogenet Evol. 2012;62(3):1009-12.

70. Roe AD, Sperling FAH. Patterns of evolution of mitochondrial cytochrome c oxidase I and II DNA and implications for DNA barcoding. Mol Phylogenet Evol. 2007;44(1):325-45.

71. Pentinsaari M, Salmela H, Mutanen M, Roslin T. Molecular evolution of a widely-adopted taxonomic marker (COI) across the animal tree of life. Sci Rep. 2016;6:35275.

72. Wainwright BJ, I Y YCA, Neo ML, Chang JJM, Gan CZ, Clark-Shen N, et al. DNA barcoding of traded shark fins, meat and mobulid gill plates in Singapore uncovers numerous threatened species. Conserv Genet. 2018;19(6):1393-9.

73. But GW-C, Wu H-Y, Shao K-T, Shaw P-C. Rapid detection of CITESlisted shark fin species by loop-mediated isothermal amplification assay with potential for field use. Sci Rep. 2020;10(1):4455.

74. van der Loos LM, Nijland R. Biases in bulk: DNA metabarcoding of marine communities and the methodology involved. Mol Ecol. 2021;30(13):3270-88.

75. Collins RA, Bakker J, Wangensteen OS, Soto AZ, Corrigan L, Sims DW, et al. Non-specific amplification compromises environmental DNA metabarcoding with COI. Methods Ecol Evol. 2019;10(11):1985-2001.

76. Valsecchi E, Bylemans J, Goodman SJ, Lombardi R, Carr I, Castellano L, et al. Novel universal primers for metabarcoding environmental DNA surveys of marine mammals and other marine vertebrates. Environ DNA. 2020;2(4):460-76.

77. Yeo D, Srivathsan A, Meier R. Longer is not always better: optimizing barcode length for large-scale species discovery and identification. Syst Biol. 2020;69(5):999-1015.

78. Sevilla RG, Diez A, Norén M, Mouchel O, Jérôme M, Verrez-Bagnis $V$, et al. Primers and polymerase chain reaction conditions for DNA barcoding teleost fish based on the mitochondrial cytochrome $b$ and nuclear rhodopsin genes. Mol Ecol Notes. 2007;7(5):730-4.

79. Chagas ATdA, Ludwig S, Pimentel JdSM, de Abreu NL, NunezRodriguez DL, Leal HG, et al. Use of complete mitochondrial genome sequences to identify barcoding markers for groups with low genetic distance. Mitochondrial DNA A. 2020;31(4):139-46.

80. Last PR, Naylor GJP, Manjaji-Matsumoto BM. A revised classification of the family Dasyatidae (Chondrichthyes: Myliobatiformes) based on new morphological and molecular insights. Zootaxa. 2016:4139(3):345-68.

81. Truelove NK, Andruszkiewicz EA, Block BA. A rapid environmental DNA method for detecting white sharks in the open ocean. Methods Ecol Evol. 2019;10(8):1128-35

82. Larsen FW, Bladt J, Rahbek C. Improving the performance of indicator groups for the identification of important areas for species conservation. Conserv Biol. 2007;21(3):731-40.

83. Handley LL, Read DS, Winfield IJ, Kimbell H, Johnson H, Li J, et al. Temporal and spatial variation in distribution of fish environmental DNA in England's largest lake. Environ DNA. 2019;1 (1):26-39.

84. Kelly RP. Making environmental DNA count. Mol Ecol Resour. 2016;16(1):10-2.

85. Rourke ML, Fowler AM, Hughes JM, Broadhurst MK, DiBattista JD, Fielder S, et al. Environmental DNA (eDNA) as a tool for assessing fish biomass: a review of approaches and future considerations for resource surveys. Environ DNA. 2021.

86. Li W, Hou X, Xu C, Qin M, Wang S, Wei L, et al. Validating eDNA measurements of the richness and abundance of anurans at a large scale. J Anim Ecol. 2021;90(6):1466-79.

87. Muri CD, Di Muri C, Handley LL, Bean CW, Li J, Peirson G, et al. Read counts from environmental DNA (eDNA) metabarcoding reflect fish abundance and biomass in drained ponds. Metabarcoding Metagenomics. 2020;4:e56959.

88. Laporte M, Reny-Nolin E, Chouinard V, Hernandez C, Normandeau E, Bougas B, et al. Proper environmental DNA metabarcoding data transformation reveals temporal stability of fish communities in a dendritic river system. Environm DNA. 2021

89. Ushio M, Murakami H, Masuda R, Sado T, Miya M, Sakurai S, et al. Quantitative monitoring of multispecies fish environmental DNA using high-throughput sequencing. Metabarcoding Metagenomics 2018:2:e23297.
90. Barnes MA, Turner CR. The ecology of environmental DNA and implications for conservation genetics. Conserv Genet. 2016;17:1-17.

91. Bani A, De Brauwer M, Creer S, Dumbrell AJ, Limmon G, Jompa J, et al. Informing marine spatial planning decisions with environmental DNA. In: Dumbrell AJ, Turner EC, Fayle TM, editors., et al., Advances in ecological research. London: Academic Press; 2020. p. 375-407.

92. Blasiak R, Wynberg R, Grorud-Colvert K, Thambisetty S, Bandarra NM, Canário AVM, et al. The ocean genome and future prospects for conservation and equity. Nat Sustain. 2020;3(8):588-96.

93. Gauthier M, Konecny-Dupré L, Nguyen A, Elbrecht V, Datry T, Douady $C$, et al. Enhancing DNA metabarcoding performance and applicability with bait capture enrichment and DNA from conservative ethanol. Mol Ecol Resour. 2020;20(1):79-96.

94. Baerwald MR, Goodbla AM, Nagarajan RP, Gootenberg JS, Abudayyeh $\mathrm{OO}$, Zhang $\mathrm{F}$, et al. Rapid and accurate species identification for ecological studies and monitoring using CRISPR-based SHERLOCK. Mol Ecol Resour. 2020;20(4):961-70.

95. Williams M-A, O'Grady J, Ball B, Carlsson J, de Eyto E, McGinnity P, et al. The application of CRISPR-Cas for single species identification from environmental DNA. Mol Ecol Resour. 2019;19(5):1106-14.

96. Turon X, Antich A, Palacín C, Praebel K, Wangensteen OS. From metabarcoding to metaphylogeography: separating the wheat from the chaff. Ecol Appl. 2020;30(2):e02036.

97. Tsuji S, Maruyama A, Miya M, Ushio M, Sato H, Minamoto T, et al. Environmental DNA analysis shows high potential as a tool for estimating intraspecific genetic diversity in a wild fish population. Mol Ecol Resour. 2020;20(5):1248-58.

98. Ward RD, Zemlak TS, Innes BH, Last PR, Hebert PDN. DNA barcoding Australia's fish species. Philos Trans R Soc B Biol Sci. 2005;360(1462):1847-57.

99. Fields AT, Abercrombie DL, Eng R, Feldheim K, Chapman DD. A novel mini-DNA barcoding assay to identify processed fins from internationally protected shark species. PLoS ONE. 2015;10(2):e0114844.

100. Meier R, Wong W, Srivathsan A, Foo M. \$1 DNA barcodes for reconstructing complex phenomes and finding rare species in specimenrich samples. Cladistics. 2016;31(1):100-10.

101. Smith DP, Peay KG. Sequence depth, not PCR replication, improves ecological inference from next generation DNA sequencing. PLoS ONE. 2014;9(2):e90234.

102. Zhang J, Kobert K, Flouri T, Stamatakis A. PEAR: a fast and accurate Illumina Paired-End reAd mergeR. Bioinformatics. 2014;30(5):614-20.

103. Boyer F, Mercier C, Bonin A, Le Bras Y, Taberlet P, Coissac E. obitools: a unix-inspired software package for DNA metabarcoding. Mol Ecol Resour. 2016;16(1):176-82.

104. Martin M. Cutadapt removes adapter sequences from high-throughput sequencing reads. EMBnet.j. 2011;17(1):10.

105. Camacho C, Coulouris G, Avagyan V, Ma N, Papadopoulos J, Bealer K, et al. BLAST: architecture and applications. BMC Bioinform. 2009;10(1):421.

106. Srivathsan A, Sha JCM, Vogler AP, Meier R. Comparing the effectiveness of metagenomics and metabarcoding for diet analysis of a leaf-feeding monkey (Pygathrix nemaeus). Mol Ecol Resour. 2015;15(2):250-61.

107. Hebert PDN, Cywinska A, Ball SL, deWaard JR. Biological identifications through DNA barcodes. Proc R Soc Lond B. 2003:270(1512):313-21.

108. Škaloud P, Moya P, Molins A, Peksa O, Santos-Guerra A, Barreno E. Untangling the hidden intrathalline microalgal diversity in Parmotrema pseudotinctorum: Trebouxia crespoana sp. nov. Lichenologist. 2018;50(3):357-69.

109. Kindt R, Kindt MR. Package 'BiodiversityR'. Package for community ecology and suitability analysis. 2019;2-11.

110. Oksanen J, Blanchet FG, Kindt R, Legendre P, Minchin PR, O'hara RB, et al. Package 'vegan'. Community ecology package, version. 2013;2(9):1-295.

111. Ip YCA, Chang JJM, Lim KKP, Jaafar Z, Wainwright BJ, Huang D. Seeing through sedimented waters: environmental DNA reduces the phantom diversity of sharks and rays in turbid marine habitats. NCBI SRA. https:// www.ncbi.nlm.nih.gov/bioproject/PRJNA673533. Accessed 9 Aug 2021.

\section{Publisher's Note}

Springer Nature remains neutral with regard to jurisdictional claims in published maps and institutional affiliations. 